\title{
The link between health and wellbeing and constitutional recognition
}

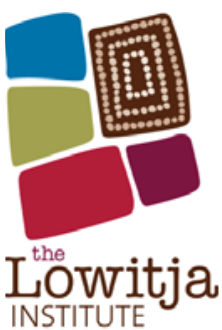

$\mathrm{T}$ he Lowitja Institute is Australia's national institute for Aboriginal and Torres Strait Islander health research. It is an Aboriginal and Torres Strait Islander organisation, named in honour of its patron $\mathrm{Dr}$ Lowitja O'Donoghue, AC, CBE, DSG. The Institute was established in 2010, emerging from a 14-year history of cooperative research centres.

The Lowitja Institute has led an initiative called Recognise Health, which promotes understanding of the important link between health and wellbeing and constitutional recognition of Aboriginal and Torres Strait Islander people. The initiative has brought together a coalition of 125 leading non-government organisations across the Australian health system in support of constitutional recognition. These organisations have signed the following statement (https://www.lowitja.org. $\mathrm{au} /$ recognisehealth/statement).

We call on all Australians to support recognition of Aboriginal and Torres Strait Islander peoples in the Australian Constitution.

We look forward to a time when all Aboriginal \& Torres Strait Islander people can fully participate in all that Australia has to offer, enjoying respect for our country's first cultures and leadership, and the dignity and benefits of long healthy lives.

Australia's First Peoples continue to die far earlier and experience a higher burden of disease and disability than other Australians. This is a result of long term economic disadvantage and social exclusion, among other factors. Constitutional recognition would provide a strong foundation for working together towards better health and social wellbeing in the hearts, minds and lives of all Australians.

Recognise Health was launched at Parliament House in Canberra on 5 March 2015, with parliamentarians, medical and health leaders and community representatives present, in a strong show of commitment to the initiative.

The Australian Constitution, the main law that guides the operation of the Commonwealth of Australia, took effect in 1901. At that point in time, Aboriginal and Torres
Strait Islander people had lived on this land for thousands of generations, keeping alive the world's oldest living continuous cultures. However, Australia's founding document does not recognise this first chapter of our national story.

Following the 2012 report of the Expert Panel on Constitutional Recognition of Indigenous Australians, all major political parties declared their support for recognition. Subsequently, the Prime Minister announced that the government intends to work towards a referendum. For the referendum to pass, the people of Australia need to understand and support the case for change, and there needs to be strong leadership from across the political spectrum, business and community sectors, and, of course, by Aboriginal and Torres Strait Islander leaders. Part of the work required for a successful referendum is to engage key community organisations such as health organisations - in the national dialogue, thereby engaging their membership and the broader public to support the referendum.

Recognition of Aboriginal and Torres Strait Islander people would acknowledge their powerful sense of identity, pride, history and belonging to this land. It would promote opportunities for full participation in all that Australia has to offer and would be a significant step towards equity between Indigenous and non-Indigenous Australia.

Recognition, participation and equity would, in turn, have profound positive consequences for wellbeing, and therefore health. There is significant evidence from health research to indicate that being connected to the wider community, having a strong identity and feeling socially supported all have significant positive impacts on health.

The role of social and economic factors in determining health status is well understood; health does not exist within a vacuum. It is intricately connected to education, employment, housing, and more. Cultural factors also have a profound impact. Having a strong sense of identity and pride - individually and communally - has a supportive, protective and healing influence. Unfortunately, how we experience the great benefits of modern medical science has become disconnected from cultural, community, social and economic contexts.

As Aboriginal singer and performer Archie Roach stated at the launch of Recognise Health: "I really believe that being recognised within the Constitution has a lot to do with how we feel about ourselves, that we are worthy and we can be proud of my people" (http://www.recognise. org.au/blogs/ourstory).

The Institute has worked closely with Recognise (http:// www.recognise.org.au), the people's movement to recognise Aboriginal and Torres Strait Islander people in the Australian Constitution, on this initiative. More information, including a short film featuring five health leaders, is available at https://www.lowitja.org.au/ recognisehealth. 

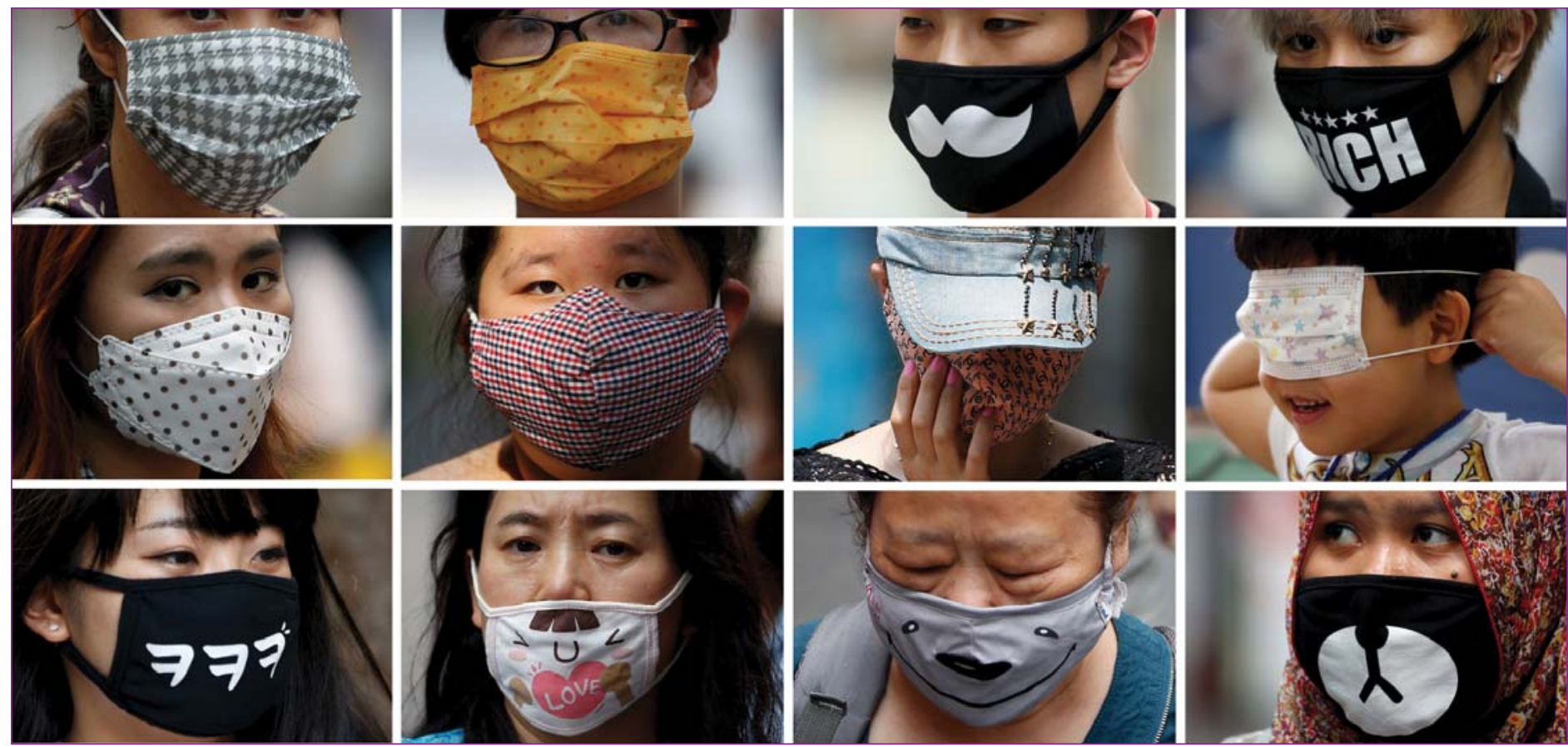

A collage of pictures showing South Koreans wearing masks to protect themselves against Middle East respiratory syndrome (MERS) in Seoul.

\section{Promising signs for dabigatran reversal}

Clinical tests of a reversal agent for the anticoagulant effect of oral thrombin inhibitor dabigatran have been promising, reports Medscape. An international open-label trial with an expected enrolment of 250 to 300 "high-risk patients undergoing emergency surgery or suffering from life-threatening bleeding" is ongoing, but investigators presented early results at the International Society on Thrombosis and Haemostasis 2015 Congress in Toronto, Canada. "Based on these data, what idarucizumab does is very predictably and very effectively take anticoagulation off the list of concerns of the treating physician", lead investigator Dr Charles Pollack told Medscape. "It doesn't close up holes in vessels, it doesn't stop hematomas in the head from expanding, but it does remove any concern the provider might have about dabigatran so he/she can move forward and deal with the underlying issues."

\section{The skinny on jeans and squatting}

\section{Australian}

researchers

published in the Journal of Neurology, Neurosurgery and Psychiatry have described a case of a woman who experienced nerve damage bad enough to cause numbness and hospital care after a day spent squatting in skinny jeans, TIME reports. The woman was helping a relative move house, and spent the day squatting while packing boxes. On her walk home, her feet went numb, she fell, and was taken to hospital. "Her legs and ankles had become so swollen that emergency room staff had to cut her jeans off", TIME reports. "Her ankles and toes were weak, but the rest of her legs, including her knees and hips, were working normally. When the doctors did studies on how her leg nerves were functioning, they found blockage of the nerve that directs the lower leg and feet. The squatting probably squashed the nerves feeding into each leg, and the skinny jeans didn't help when the swelling started, further constricting them and crushing the nerves." The woman was released from hospital 4 days later.

\section{Fake cardiologist's letter retracted}

The Journal of the American College of Cardiology has been forced to retract a letter published in 2014 because they were unable to identify the author, Retraction Watch reports. The letter was published under the authorship of "Erling Falk from the University of Copenhagen", but when the real Erling Falk, of Aarhus University, contacted the editors asking who wrote the letter, they discovered nobody of that name worked at the University of Copenhagen. The mystery author corresponded with the editors during the review process, but did not respond after publication. "Due to an inability to confirm the identity of this author, the JACC editors felt it necessary to retract the Letter to the Editor", the Journal confirmed. The letter was "wellwritten", said the real Dr Falk, but he was "not happy with my name being connected to a retracted paper". 


\section{Top 5 MJA articles online since 1 June 2015}

1) Perspective: The scourge of managerialism and the Royal Australasian College of Physicians

The managerialist organisational model has penetrated deeply into our institutions, with destructive consequences doi: 10.5694/mjal5.00170

2) Perspective: Response - The Royal Australasian College of Physicians: a 21st century college doi: 10.5694/mja15.00609

3) Research: The crux of the matter: did the ABC's Catalyst program change statin use in Australia?

doi: 10.5694/mja15.00103

4) Research: The services provided to young people by headspace centres in Australia doi: 10.5694/mjal4.01695

5) Research: Changes in psychological distress and psychosocial functioning in young people visiting headspace centres for mental health problems doi: 10.5694/mjal4.01696

\section{Meanwhile, in MJA InSight ...}

\section{Autopsy nears "extinction"}

"With a reduction in the number of hospital autopsies being performed, there's a lesser need for pathologists-in-training to learn how to do it" - Associate Professor David Ranson, deputy director of the Victorian Institute of Forensic Medicine https://www.mja.com.au/insight/2015/23/autopsy-nears-extinction

\section{New focus on chronic fatigue}

"I really empathise with GPs because there is an extraordinary range of reasonably common clinical conditions that also produce debilitating fatigue" - Professor Donald Staines, co-director of Griffith University's National Centre for Neuroimmunology and Emerging Diseases https://www.mja.com.au/insight/2015/23/new-focus-chronic-fatigue

\section{Patrick Charles: Power of poo}

"[Faecal microbiota transplant] obviously can have potential problems, not least of which is the "gross out' factor" -

Associate Professor Patrick Charles, physician in Infectious Diseases and General Medicine at Austin Health, Melbourne https://www.mja.com.au/insight/2015/22/patrick-charles-power-poo

\section{MJA Podcast}

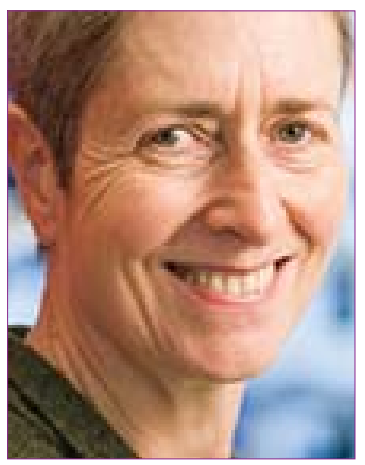

Professor Anne Kelso

\section{Professor Anne Kelso, AO}

Chief executive officer of the National Health and Medical Research Council.

Professor Kelso was previously director of the World Health

Organization Collaborating Centre for Reference and Research on Influenza in Melbourne. She talks about her vision for the NHMRC and current issues of funding for medical research.

\section{Geoff Down}

Curator of the Rare and Historical Books Collection at the Royal Australasian College of Surgeons.

Geoff Down speaks about the Lewis Cowlisham Collection, which consists of around 2000 medical texts and histories dating back to the 14 th century. This priceless collection will be part of a special presentation during Melbourne Rare Book Week this month.

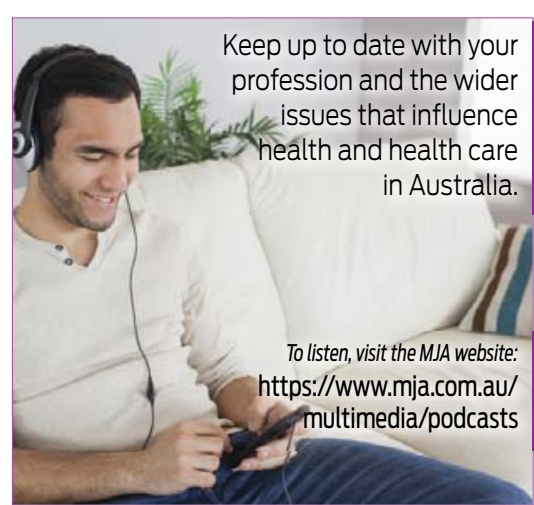

